\title{
Doğuştan çarpık ayakta klinik değerlendirme ve deformiteler
}

\author{
Clinical evaluation and deformities of congenital clubfoot
}

\author{
Ahmet Doğan \\ İstanbul Kemerburgaz Üniversitesi Tıp Fakültesi, Ortopedi ve Travmatoloji Anabilim Dalı, İstanbul
}

\begin{abstract}
Çarpık ayak, temel olarak dört komponenti olan bir deformitedir; ekinus, varus, adduktus ve kavus. Çarpık ayaklı bir hastada deformite komponentlerinin sertlik ve ağırlık derecesi değişkenlik gösterebilir. Sıra dışı bir durum olmadıkça, normal şartlarda radyografik değerlendirmeye gerek yoktur. Ayrıntılı bir klinik muayene, deformitenin tüm komponentleriyle değerlendirilmesine olanak sağlayacaktır. Çocuk ayağı konusunda yeterli tecrübeye sahip bir ortopedist, muayene esnasında kemiklerin ve eklemlerin durumunu, yer değiştirme derecelerini disseke edilmiş bir ayağın fotoğrafına bakar gibi üç boyutlu olarak kafasında canlandırabilir.
\end{abstract}

Çarpık ayak olgularının gerek tedavi öncesi, gerekse tedavi sonrası klinik değerlendirmesi ile ilgili yayımlanmış birçok yöntem olmasına rağmen, üzerinde mutabakata varılmış, standardize edilmiş bir yöntem yoktur. Bu amaçla geliştirilmiş, günümüzde en çok kabul gören yöntemlerden biri, Dimeglio ve arkadaşlarının geliştirdiği skorlama sistemidir. Bu sistem, her biri dört puan üzerinden değerlendirilmek üzere, dört parametre üzerindeki ölçümlere dayanan bir puanlama sistemidir. Puanlar daha sonra hastalığın ağırlığı ve tedaviye yanıt hakkında bilgi veren derecelere dönüştürülür.

Anahtar sözcükler: çarpık ayak; doğumsal kusurlar; talipes equinovarus; Ponseti
Basically, clubfoot is a deformity with 4 components; equinus, varus, adductus and cavus. The severity and the stiffness of the components may vary in a clubfoot. Normally, radiographical evaluation is not required and performed only in extraordinary conditions. A thorough physical examination helps to evaluate the deformity with all of the components. An orthopaedic surgeon who is experienced on pediatric foot can imagine a three-dimensional scene of the foot, and understand the position and displacement degree of the bones and the joints as if he was looking at it anatomically dissected.

Although there are numerous methods suggested for the clinical evaluation before and after the treatment of the clubfoot cases, there is not a consensus on standardized method. Currently, the most accepted method is the scoring system suggested by Dimeglio et al. This is a scoring system based on measurements of the 4 parameters which are evaluated over 4 points each. The points are then converted to the degrees which inform about the severity of the deformity and its response to treatment.

Key words: clubfoot; congenital defects; talipes equinovarus; Ponseti

blok olarak talusun etrafinda internal rotasyonu ve ayağın ön kısmının arkasına göre adduksiyonu ve kavus. ${ }^{[1-3]}$ Tüm çarpık ayak olgularında deformite aynı değildir. Çarpık ayaklı bir hastada, deformite komponentlerinin sertlik ve ağırlık derecesi değişkenlik gösterebilir. ${ }^{[2]}$ Hastalığın ağırlık derecesini belirlemek için dikkate alınması gereken en önemli faktörler; baldır kaslarının ebadında azalma ve proksimal retraksiyonun derecesi, topuğun ekin ve varusunun ağırlığı, ayak ön kısmı adduksiyonunun sertliği, talusun mediyale kaymasının derecesi ve ayak bileği arkasında ve ayağın plantar-mediyal yüzündeki cilt katlantılarının derinliği olarak sıralanır. ${ }^{[2]}$ Önemli olan,
Çarpık ayak, temel olarak dört komponenti olan bir deformitedir; sagittal planda ekinus, frontal planda varus, horizontal planda tüm ayağın kalkaneopedal

- İletişim adresi: Doç. Dr. Ahmet Doğan, Bahçeşehir 1. Kısım, 2801 Sok. Kelebekler Vadisi Sitesi, C24, 6AN, Başakşehir, İstanbul Tel: 0532 - 2510411 e-posta: orthopaedy@hotmail.com

- Geliş tarihi: 25 Mayıs 2015 Kabul tarihi: 25 Mayıs 2015 


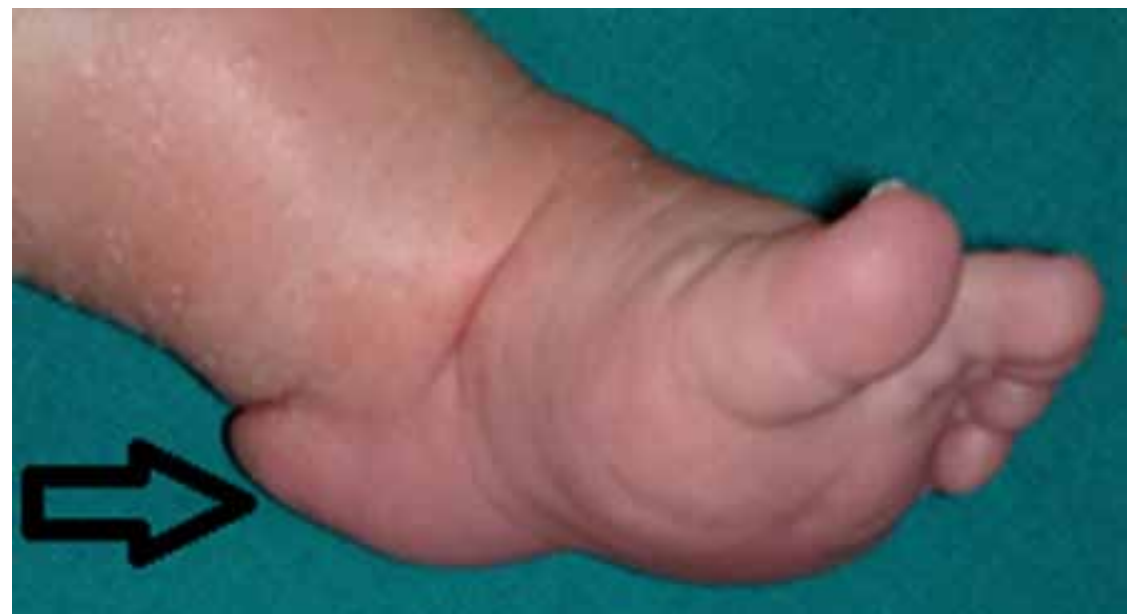

Şekil 1. Kalkaneusun ekinusuna bağlı boş topuğun klinik görünümü.

tek başına deformitenin şiddetinden ziyade, ayağın esnekliği(redükte edilebilirliği)dir. ${ }^{[2,4]}$

Normal şartlarda, sıra dışı bir durum olmadıkça, radyografik değerlendirmeye gerek yoktur. ${ }^{[1,2,5]}$ Erken bebeklik döneminde tarsal kemiklerin gerçek durumlarının değerlendirilmesi, görünür üç tarsal kemiğin (talus, kalkaneus, küboid) ossifikasyon merkezleri küçük, dikdörtgen ve eksentrik yerleşimli olduğu için, ancak izafi olarak yapılabilir. ${ }^{[2]}$ Ayrıca, üç planlı bir deformitenin iki planlı görüntüsü yanlış yorumlamalara yol açabilir. Burada, klinik değerlendirmenin önemi ortaya çıkmaktadır ve palpasyon esastır. ${ }^{[1,5]}$ Çocuk ayağı konusunda yeterli tecrübeye sahip bir ortopedist, muayene esnasında kemiklerin ve eklemlerin durumunu, yer değiştirme derecelerini disseke edilmiş bir ayağın fotoğrafına bakar gibi üç boyutlu olarak kafasında canlandırabilir.

Çarpık ayağı standart olarak tedaviye başlamadan önce ve tedavinin her aşamasında, özellikle alçılama periyodunda her alçılamadan önce, mutlaka değerlendirme yapılmalıdır. Ayak, ayak bileği ve bacakların torsiyonel durumu, varus ya da valgus pozisyonu, şekli ve boyutları değerlendirilmelidir. Çarpık ayaklı bir hastada mediyal malleolar çıkıntı naviküler tarafından gizlendiği için, klinik olarak torsiyonu değerlendirmek çok mümkün olmayabilir. Çarpık ayak, normal ayağa nazaran boyut olarak daha küçük ve baldır kısmı da daha atrofiktir. ${ }^{[1,2,5]}$ Ebeveynler, genellikle bu durumu alçı tedavisine bağlar, bundan dolayı tedavinin başlangıcında, bunun aslında hastalığın bir doğası olduğu konusunda bilgilendirilmeleri gerekir. Özellikle tek taraflı olgularda, bacak boyları arasında fark beklenmez. ${ }^{1]}$

Deformitenin her bir komponenti ayrı ayrı incelenmelidir. Ekinus, diz hem ekstansiyonda hem de fleksiyonda iken değerlendirilmelidir. Gastroknemiussoleus kas kompleksinin gerçek anlamdaki kontraktürünü, bunun çift eklemli bir kas olması nedeniyle, diz ekstansiyonda iken yapılan değerlendirme daha doğru verir. Ekinus değerlendirilirken dikkat edilmesi gereken bir diğer nokta, topuk varusunun ve subtalar internal rotasyonun maksimal düzeltilmiş pozisyonunda iken değerlendirilmesi gerektiğidir. Ayak bu pozisyonda iken, kalkaneus dikkatlice palpe edilmelidir. Klinik olarak topuk yastığı normal görünse bile, kalkaneus ekinusta olabilir ve proksimalde posterior cilt katlantısına yakın bir bölgede palpe edilir. Aynı zamanda, muayene eden kişi topuk yastığının boş olduğunu hissedecektir (Şekil 1).

Çarpık ayakta kalkaneus, inversiyon, adduksiyon ve ekinustadır. Topuk varusu, ayağın hem doğal halinde hem de maksimal korrekte pozisyonunda iken ölçülmelidir. Topuk varusunun düzeltilmesinin kalkaneusu eversiyona getirerek sağlanamayacağı unutulmamalıdır. Topuk varusunun düzeltilmesi, topuğa dokunulmadan talusun distalindeki tüm ayağın monoblok olarak abduksiyonu ile kendiliğinden olur. Bu manevra ile, kalkaneus eversiyona, kendi normal nötral pozisyonuna gelecektir. Çarpık ayaklı hastalarda subtalar eklemin fleksibilitesini değerlendirmek güçtür; ancak, ayağın sertlik derecesi hakkında bilgi verebilir. Özellikle seri alçılamadan sonra devam eden topuk varusu, kalkaneoküboid eklem ya da metatarsal varus deformitesinin göstergesi olabilir. ${ }^{[1]}$

Çarpık ayağın konservatif tedavisinde manipülasyonun en önemli noktalarından biri, talus başının tam ve doğru olarak lokalize edilmesidir (Şekil 2). Plantar fleksiyonda kilitli olmasına rağmen, genellikle ayağın dorsolateralinde ve tibial tüberkül ve krest ile aynı çizgi 

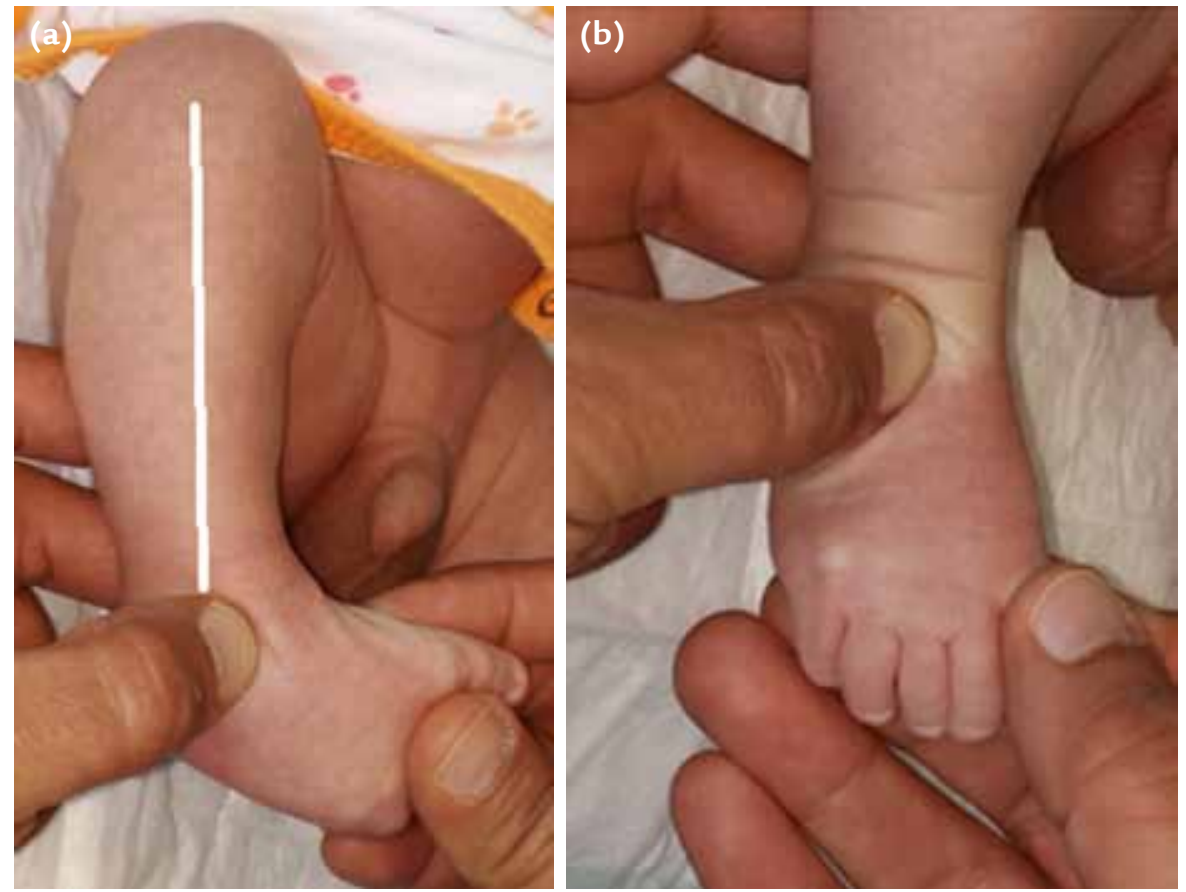

Şekil 2. a, b. Talus başının belirlenmesi. Genellikle tibial tüberkül ve krest ile aynı aksta daha anterior yerleşimlidir (a). Tüm ayağın monoblok olarak abduksiyonu-adduksiyonu ile lokalizasyonunun doğrulanması (b).

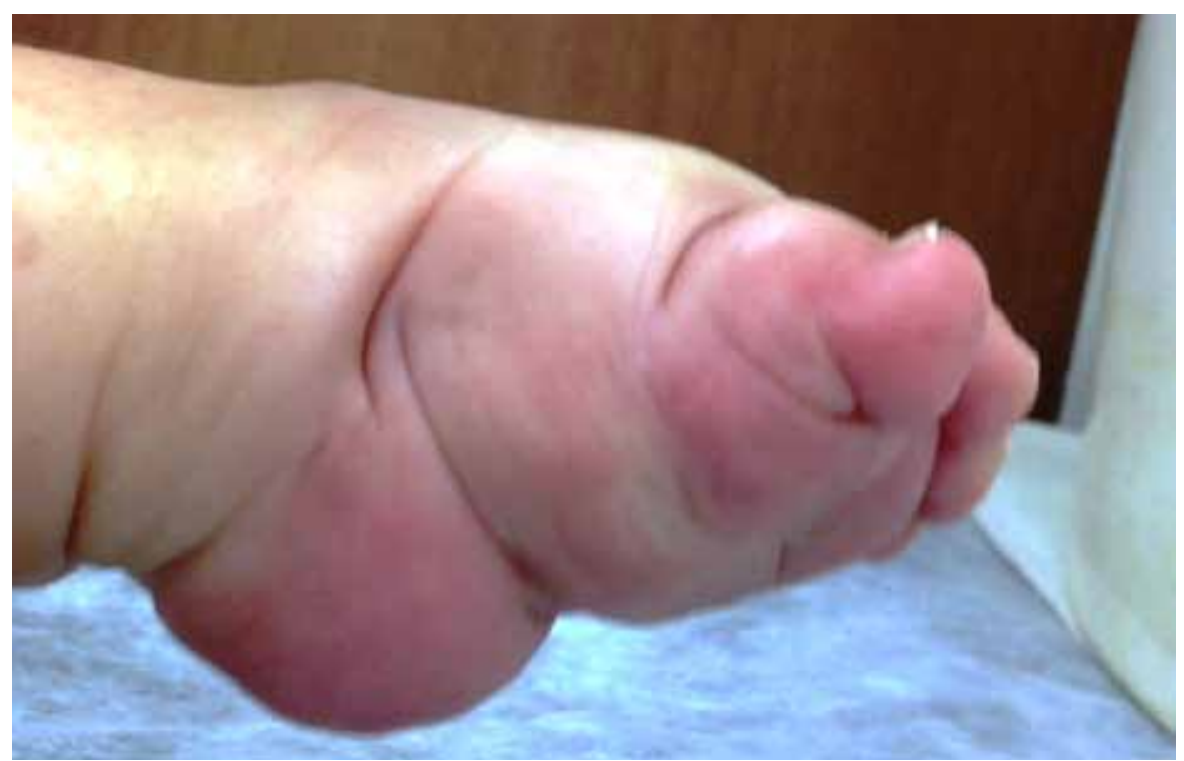

Şekil 3. Ayak plantar-mediyal yüzünde derin, anormal cilt katlantısı ve kavusun klinik görünümü.

üzerindedir. ${ }^{[2]}$ Talus başının hemen altında yer alan kalkaneusun anterior çıkıntısı ile karıştırılmamalıdır. Ayağın ön kısmının talus başı etrafında derote edilerek korrekte edilmeye çalışılması, orta ayağın sertlik derecesi hakkında bilgi verebilir. ${ }^{[1]}$

Ayak önü kavus ve supinasyonu değerlendirilmelidir. Ayak plantar-mediyal yüzünde derin bir cilt katlantısı görülecektir (Şekil 3). Bu durum, diğer bir deyişle kavus komponenti, birinci metatarsın diğer metatarslara nazaran aşıı plantar fleksiyonundan kaynaklanır. ${ }^{[2]}$ Çarpık ayakta tüm deformiteler, kendisine en yakın proksimal segmente göre değerlendirilmelidir. Ayağın ön kısmı ortasına göre, orta kısmı arkasına göre, arkası ise ayak bileğine göre değerlendirilmelidir. Çarpık ayakta, ayak bir 


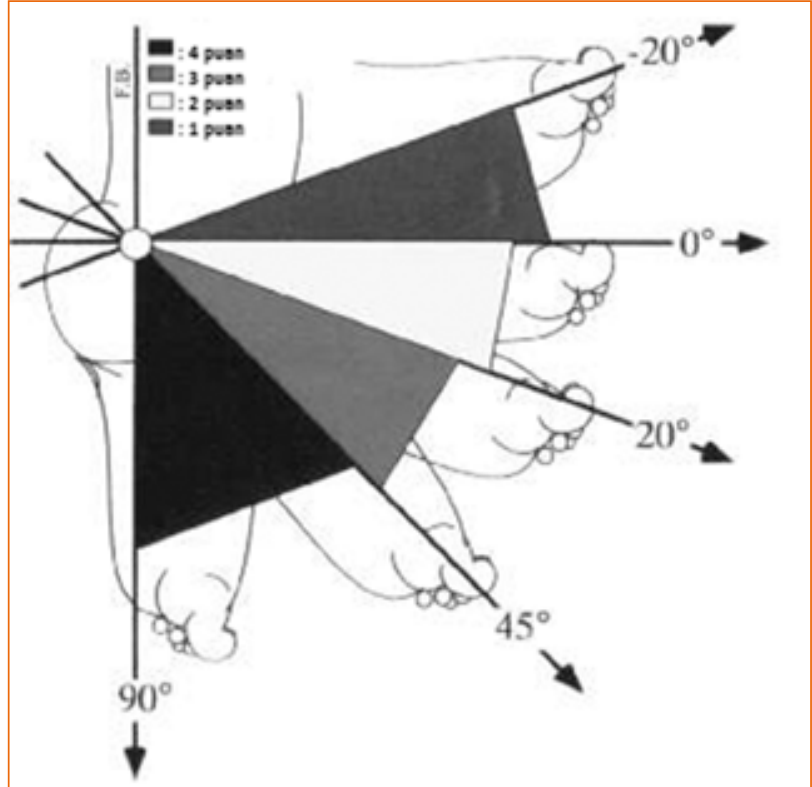

Şekil 4. Sagittal planda ekinusun değerlendirilmesi (Wolters Kluwer Health Inc. yayınevinden izin alınarak basılmıştır). ${ }^{[3]}$

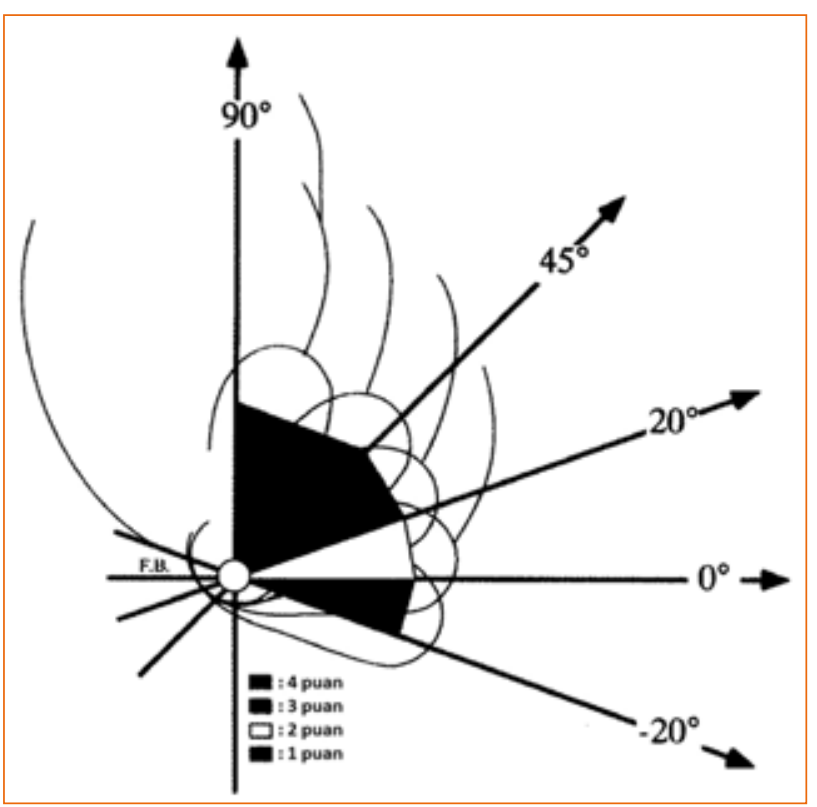

Şekil 5. Frontal planda varusun değerlendirilmesi (Wolters Kluwer Health Inc. yayınevinden izin alınarak basılmıştır). ${ }^{[3]}$ bütün olarak değerlendirildiğinde supinasyondadır; ancak, birinci metatarsın aşııı plantar fleksiyonundan dola$y ı$, ayak önü arkasına göre pronasyondadır ve kavus deformitesine neden olur (Şekil 3). Ponseti yönteminin başarılı olmasının çıkış noktası da tam buradadır. Ponseti yönteminde ilk yapılan, birinci metatarsın elevasyonu ile kavus deformitesinin düzeltilmesi, yani ayağın önü ile arkasının aynı düzleme getirilmesidir. Bu aşamada tüm ayak supinasyonda olduğu için, deneyimsiz bir ortopedistte deformitenin arttığı izlenimi uyandırabilir.

Internal tibial torsiyon, çarpık ayak deformitesinin bir bileşeni olarak kabul edilegelmiştir. Ancak, tedavi edilen birçok çarpık ayak olgusunda iddia edildiği gibi, internal tibial torsiyon yerine lateral malleolün geriye doğru yer değiştirmiş olduğu görülmüştür. Bilgisayarlı tomografi ve ultrasonografi ile yapılmış çalışmalar, çarpık ayaklı çocuklarda internal tibial torsiyon deformitesi olmayıp, normal ayaklı çocuklarda olduğunun yarısı kadar eksternal tibial torsiyon olduğunu göstermiştir. Distal fibulanın geriye kayması, hatalı tedavinin bir sonucudur ve talusun altında topuk inversiyon ve adduksiyonda kilitlenmişken, ayağın hatalı olarak abduksiyona (dış rotasyona) manipülasyonuyla olur. ${ }^{[2]}$

Çarpık ayak olgularının gerek tedavi öncesi, gerekse tedavi sonrası değerlendirilmesi ile ilgili yayımlanmış bir çok yöntem olmasına rağmen, üzerinde mutabakata varılmış, standardize edilmiş bir yöntem yoktur. ${ }^{[3,4,6-9]}$
Çarpık ayak olgularında deformitenin kompleks, üç boyutlu ve kısmen dinamik bir deformite olması nedeniyle, sınıflandırılması zordur ve bir öğrenme süreci gerektirir. İdeal bir yöntem; objektif, güvenilir, geliştirilebilir, klinik uygulama açısından pratik, tedavi seyri ve sonuçlar açısından da yol gösterici olmalıdır. Bu amaçla, günümüzde en çok kabul gören iki yöntem, Dimeglio ve Pirani skorlama sistemleridir ve bunlar nispeten ortak bir dil kullanılmasını sağlamıştır. ${ }^{[6-8]}$ Bu skorlama sistemleri, sıklıkla tedavi sürecini izlemede, tenotomi gerekliliğini, alçı sayısını ve nüks oranlarını tahmin etmede kullanılır. ${ }^{[6-9]}$

Dimeglio ve arkadaşları, her biri dört puan üzerinden değerlendirilmek üzere dört parametre üzerindeki ölçümlere dayanan bir skorlama sistemi geliş̧tirmişlerdir; [3]

- Sagittal planda ekinus (Şekil 4).

- Frontal planda varus deviyasyonu (Şekil 5).

- Kalkaneopedal bloğun talus etrafinda derotasyonu (Şekil 6).

- Horizontal planda ön ayağın arka ayağa göre adduksiyonu (Şekil 7).

Bunlara ilave olarak, varlığında birer puan eklenilmek üzere, mediyal cilt katlantısı (Şekil 3), posterior cilt katlantısı (Şekil 1), kavus (Şekil 3) ve zayıf baldır kas yapısı olmasını da değerlendirmeye katmışlardır. Puanlar, daha sonra hastalığın ağırlığı ve tedaviye yanıt hakkında bilgi veren derecelere dönüştürülür (Tablo 1). ${ }^{[3]}$ 


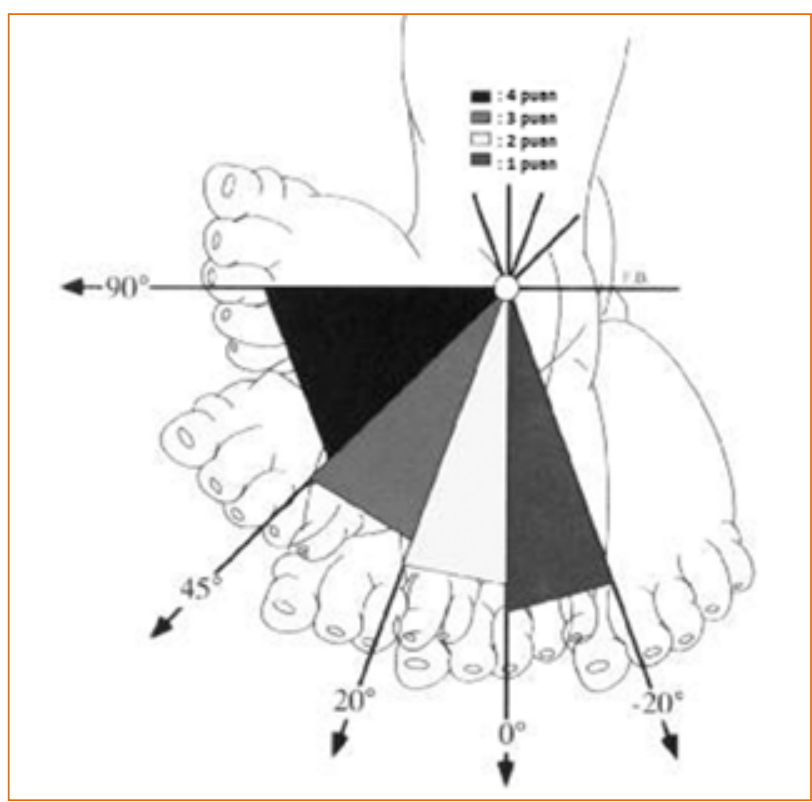

Şekil 6. Horizontal planda kalkaneopedal bloğun talus etrafinda derotasyonunun değerlendirilmesi (Wolters Kluwer Health Inc. yayınevinden izin alınarak basılmıştır)..$^{[3]}$

Pirani ve arkadaşları da altı klinik parametreye dayanan basit bir skorlama sistemi geliştirmişlerdir. ${ }^{[4]} \mathrm{Her}$ biri aşağıda belirtilen prensiplere göre skorlanır:

0 : anormallik yok

0,5 : orta derece anormallik

1 : ciddi anormallik

Altı parametrenin üçü ayak arka kısmı (ekinusun rijiditesi, posterior cilt katlantısının şiddeti ve topuk yastığının boş olup olmaması) üçü de ayak orta kısmı (ayağın lateral kenarının kurvatürü, mediyal cilt katlantısının şiddeti ve talus başının lateral kısmının pozisyonu) ile ilgilidir. ${ }^{[4]}$

Ayırıcı tanıda, ağır metatarsus adduktus olgularından ayırt edilmelidir ve benzer şekilde tedavi edilmemelidir. Sonuç, korkunç edinsel ayak valgus deformitesi

Tablo 1. Diméglio sınıflamasında hastalığın ağırlık derecesinin belirlenmesi

\begin{tabular}{ccc}
\hline Derece & Tip & Skor \\
\hline I & Benign & $<5$ \\
III & Orta & $5-10$ \\
IV & Ağır & $10-15$ \\
& Çok ağır & $15-20$
\end{tabular}

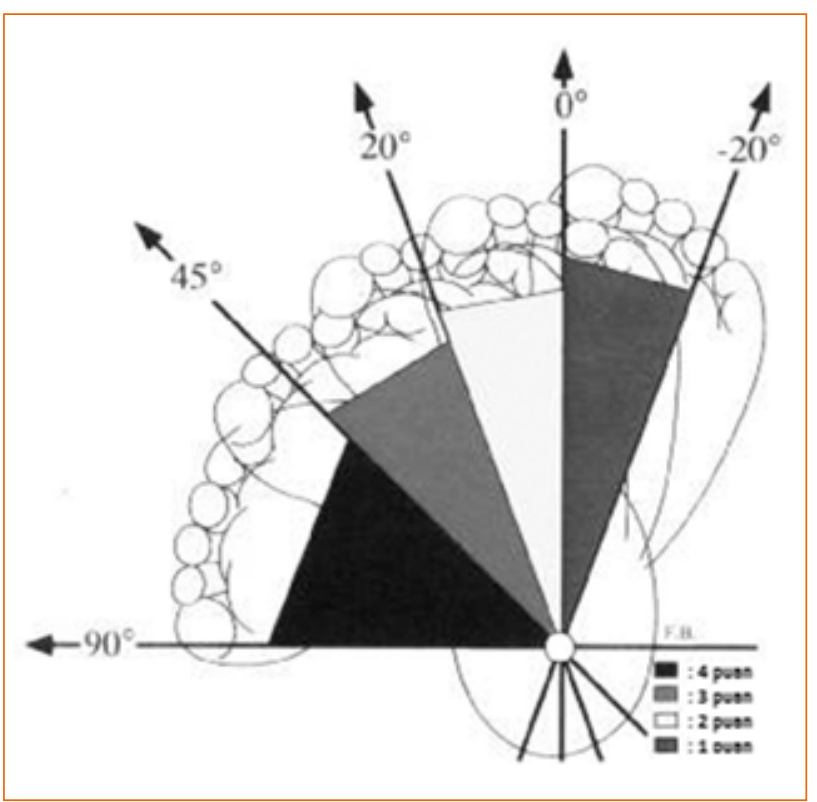

Şekil 7. Horizontal planda ön ayağın arka ayağa göre adduksiyonunun değerlendirilmesi (Wolters Kluwer Health Inc. yayınevinden izin alınarak basılmıştır). ${ }^{[3]}$

olur. Metatarsus adduktus, ekin olmadığı için kolayca ayırt edilir. Ağırlık derecesine bağlı olmakla birlikte, sıklıkla kendiliğinden düzelir.

\section{KAYNAKLAR}

1. Cummings RJ, Davidson RS, Armstrong PF, Lehman WB. Congenital clubfoot. Instructional Course Lecture. AAOS J Bone Joint Surg Am 2002;84-A:290-308.

2. Ponseti IV, Congenital Clubfoot: Fundamentals of treatment. Oxford, England: Oxford University Press; 1996.

3. Diméglio $A$. Bensahel $H$, Souchet $P$, Mazeau $P$, Bonnet $F$. Classification of clubfoot. J Pediatr Orthop B 1995;4(2):129-36.

4. Pirani $S$, Outerbridge $H$, Moran $M$, et al. A method of evaluating the virgin clubfoot with substantial inter-observer reliability. POSNA 1995; Miami, FL.

5. Siapkara A, Duncan R. Congenital talipes equinovarus: a review of current management. J Bone Joint Surg $\mathrm{Br}$ 2007;89(8):995-1000.

6. Agarwal A, Gupta N. Does initial Pirani score and age influence number of Ponseti casts in children? Int Orthop 2014;38(3):569-72. CrossRef

7. Cosma D, Vasilescu DE. A Clinical Evaluation of the Pirani and Dimeglio Idipathic Clubfoot Classifications. J Foot Ankle Surg 2015;54(4):582-5. CrossRef

8. Gao R, Tomlinson M, Walker C. Correlation of Pirani and Dimeglio scores with number of Ponseti casts for clubfoot correction. J Pediatr Orthop 2014;34(6):639-42. CrossRef

9. Dyer PJ, Davis N. The role of the Pirani scoring system in the management of club foot by the Ponseti method. J Bone Joint Surg Br 2006;88(8):1082-4. 